\title{
Hole formation and transfer in poly[9,9-di(ethylhexyl)fluorene] and an amine end-capped derivative in solution
}

\author{
H.D. Burrows ${ }^{\text {a,* }}$, J. Seixas de Melo ${ }^{\text {a }}$, M. Forster ${ }^{\text {b }}$, R. Güntner ${ }^{b}$, U. Scherf ${ }^{b}$, \\ A.P. Monkman ${ }^{\text {c }}$, S. Navaratnam ${ }^{\text {d,e }}$ \\ a Departamento de Química, Universidade de Coimbra, Rua Larga, P3004-535 Coimbra, Portugal \\ b Makromolekulare Chemie, Bergische Universität Wuppertal, D-42097 Wuppertal, Germany \\ ${ }^{\mathrm{c}}$ Department of Physics, University of Durham, Durham DH1 3LE, UK \\ ${ }^{\mathrm{d}}$ Free Radical Research Facility, Daresbury Laboratory, Warrington WA4 4AD, UK \\ ${ }^{\mathrm{e}}$ Biosciences Research Institute, University of Salford, Salford M4 4WT, UK
}

Received 13 November 2003; in final form 14 December 2003

Published online: 14 January 2004

\begin{abstract}
Pulse radiolysis has been used to study the positively charged state of isolated chains of poly[9,9-di(ethylhexyl)fluorene] in chloroform solution. This is found to have an absorption maximum at $560 \mathrm{~nm}$ and a weaker band around $420 \mathrm{~nm}$. Intermolecular electron transfer is observed from the aromatic amine tri( $p$-tolylamine) to this species. With the corresponding polyfluorene derivative end-capped by an arylamine, intramolecular transfer of electrons from the triphenylamine end-cap to the positively charged polyfluorene chain is found on timescales faster than the detection time of the system (ca. $500 \mathrm{~ns}$ ).
\end{abstract}

(C) 2003 Elsevier B.V. All rights reserved.

\section{Introduction}

Electroluminescence from conjugated organic polymers has emerged as one of the most important technologies for flat panel displays. Largely because of this it is predicted that the global market for this class of materials is going to mushroom from about three million to seven hundred million over the next three years [1]. Although the initial applications have been in monochrome displays for car radio systems and mobile phones, full colour (RGB) displays are already a reality [2] and applications in computer monitors and televisions are likely in the near future. One of the important outstanding problems is the development of efficient, stable blueemitting materials in polymer based light-emitting diodes (LEDs). Poly(9,9-dialkylfluorene)s have been shown to be good candidates for this [3-7]. However, they present two major defects for application in light emitting devices. Firstly, they tend to produce green emitting species

\footnotetext{
${ }^{*}$ Corresponding author. Fax: +351-239-827703.

E-mail address: burrows@ci.uc.pt (H.D. Burrows).
}

during fabrication or operation, which were initially attributed to formation of aggregates/excimers [5], but are now believed to be due to the presence of carbonyl defects $[7,8]$. Secondly, performance of electroluminescent devices involving these polymers is affected adversely by the charge imbalance between electrons and holes due to large injection barriers and differences in charge carrier mobilities, which can lead to increases in current but do not contribute to the emission [9]. It has been shown that incorporation of hole trapping molecules (HTM), such as aromatic amines, can dramatically increase both electroluminescence yields and colour stability of polyfluorene (PF) based LEDs, either using blends $[10,11]$ or covalently linking the HTM to poly(9,9-dialkylfluorene)s [12-14]. The hole trapping molecules are expected to act by decreasing the mobilities of the positive charge carriers, and also reducing the electric field difference between the anode and cathode. For device applications, covalent linkage of the HTM to the conjugated polymer is preferred for long term stability, since it avoids the problem of phase separation of the PF and HTM molecules. Electrochemical measurements have been made 
of the oxidation and reduction potentials of polyfluorenes and triarylamines [13-16], from which ionization potentials and electron affinities can be calculated. By suitable choice of substituents it is possible to modulate the energy gap between the HOMOs of the PF and HTM $[14,16]$.

One further current interest in poly(9,9-dialkylfluorene)s stems from their possibilities in forming liquid crystalline mesophases [17], which can be aligned on rubbed polyimide layers to give polarized LEDs [18]. It has been shown that the performance of these can be enhanced by end-capping with triarylamines [13].

Although relatively high hole mobilities have been reported for polyfluorenes [19,20], large differences are observed in values determined by time-of-flight [19] and time-resolved microwave conductivity [20] measurements. Pulse radiolysis using appropriate solvents has been shown to be an excellent technique for the specific generation and study of the behaviour of charge carriers on isolated conjugated polymer chains [20-22]. We report the application of this technique to the generation of positive charge carriers on poly[9,9-di(ethylhexyl)fluorene] (PF 2/6), together with intermolecular hole transfer to tri( $p$-tolylamine) (TTA) and intramolecular transfer within an amine end-capped polymer PF2/6am4. The structures of these systems are shown in Fig. 1.

\section{Experimental}

Poly[9,9-di(ethylhexyl)fluorene] was prepared by Yamamoto coupling [23,24], using the procedure described elsewhere [18]. The polymer was fractionated, and a relatively low molecular weight fraction (molecular weight from gel permeation chromatography: $M_{\mathrm{n}}=$ $\left.16100, M_{\mathrm{w}}=37900\right)$ was used for these studies. The amine end-capped PF2/6am4 $\left(M_{\mathrm{n}}=29200, M_{\mathrm{w}}=68200\right)$ was also synthesised by Yamamoto type polycondensation [23], adding the required amount of the end-capping reagent $N, N$-bis(4-methylphenyl)- $N$-(4-bromophenyl) amine to the reaction mixture containing monomer and catalyst, as described elsewhere [13]. From NMR spectroscopy there are on average two amine end-caps per chain, while the ratio of polyfluorene to end-cap is close to that in the monomer/end-capper feed $(96: 4 \mathrm{~mol} / \mathrm{mol}$ in this case) in the reaction mixture [13]. Chloroform was purified by washing $2.5 \mathrm{dm}^{3}$ with $250 \mathrm{~cm}^{3}$ of concentrated sulfuric acid, separating the organic layer, washing twice with distilled water $\left(2 \times 150 \mathrm{~cm}^{3}\right)$ followed by drying with magnesium sulfate. The $\mathrm{CHCl}_{3}$ was then filtered through a pad of silica gel (bottom) and sodium carbonate (top) solid and used directly. This treatment was necessary to remove ethanol stabilizer which interferes with formation of positive charged

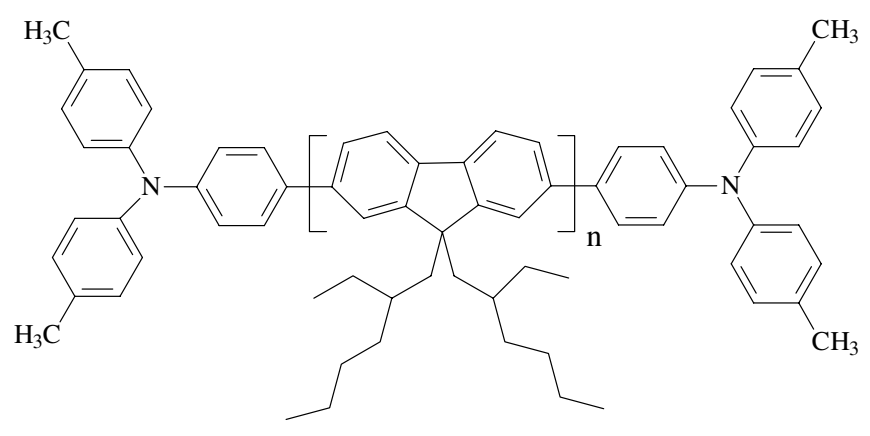

PF2/6 am4

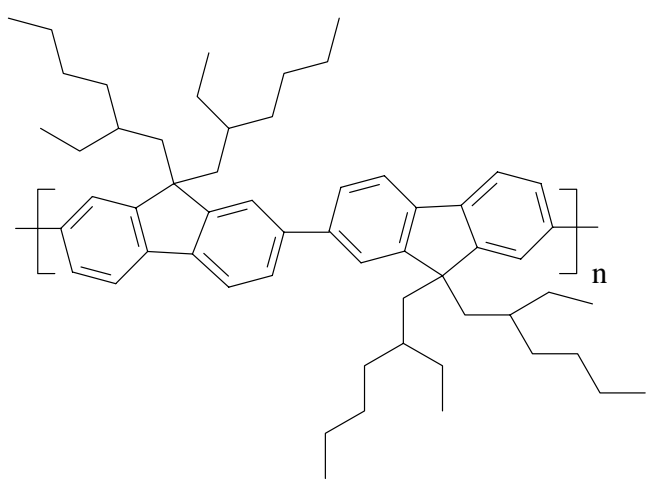<smiles>Cc1ccc(N(c2ccc(C)cc2)c2ccc(C)cc2)cc1</smiles>

Fig. 1. Structures and abbreviations of the systems studied. 
species in radiolysis. Tri( $p$-tolylamine) (Aldrich, Madrid) was used as received.

Pulse radiolysis experiments were carried out at the Free Radical Research Facility, Daresbury, UK using 200 ns $-2 \mu$ s (microseconds) high energy electron pulses from a $12 \mathrm{MeV}$ linear accelerator, which were passed through solutions in a $2.5 \mathrm{~cm}$ optical pathlength quartz cuvette attached to a flow system. All solutions were bubbled with argon for about $30 \mathrm{~min}$ before experiments. The experimental set up has been briefly described elsewhere [25]. Optical spectra, normalised for the radiation dose, were recorded using spectrometer consisting of a xenon arc lamp, monochromator, photomultiplier and appropriate filters. Signals were then directed to a computer for analysis. Spectra were taken at $10 \mathrm{~nm}$ intervals and at various times from the raw kinetic traces. Lines are given as guides to the eye. The general spectrometer design is similar to that in [26]. Dosimetry measurements were made with argon saturated solutions of tri( $p$-tolyl)amine (TTA, $10 \mathrm{mM})$ in chloroform [27].

\section{Results and discussion}

Following pulse radiolysis of an argon saturated solution of PF2/6 $\left(110 \mathrm{mg} \mathrm{dm}^{-3}\right)$ in chloroform, a transient absorption was observed with a maximum at $560 \mathrm{~nm}(2.21 \mathrm{eV})$, and a weaker band around $420 \mathrm{~nm}$ (2.95 eV, Fig. 2). Upon pulse radiolysis of pure argon saturated chloroform, there was no absorption around $560 \mathrm{~nm}$, and only a weak band was observed at $370 \mathrm{~nm}$ $\left(k=5.8 \times 10^{4} \mathrm{~s}^{-1}\right)$. This is in agreement with gamma radiolysis studies on halogenated alkanes in alkane glasses at $77 \mathrm{~K}$, where the halocarbon radical cation has a band around $370 \mathrm{~nm}$ [28]. From the known radiation chemistry of chloroform [22,27], the species absorbing at $560 \mathrm{~nm}(2.21 \mathrm{eV})$ is assigned unambiguously to the po-

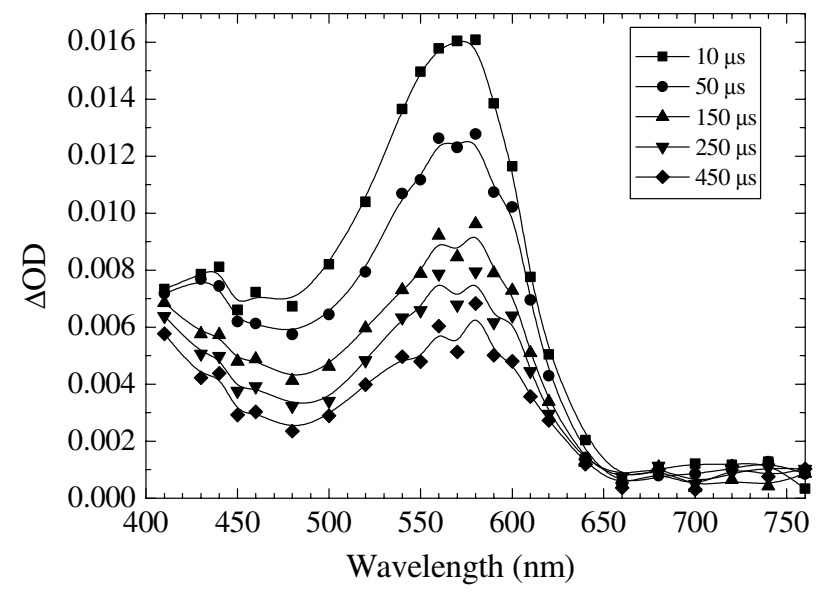

Fig. 2. Spectral data observed following pulse radiolysis of an argon saturated solution of PF2/6 $\left(110 \mathrm{mg} \mathrm{dm}^{-3}\right)$ in chloroform. sitive charge carrier (also described as positive polaron or radical cation) of PF $2 / 6$ formed by one-electron oxidation by chloroform radical cation in the reaction sequence

$$
\begin{aligned}
& 2 \mathrm{CHCl}_{3} \sim \sim \mathrm{CHCl}_{3}^{+}+\mathrm{CHCl}_{2}+\mathrm{Cl}^{-} \\
& \mathrm{CHCl}_{3}^{+}+\mathrm{PF} 2 / 6 \rightarrow \mathrm{CHCl}_{3}+\mathrm{PF} 2 / 6^{+}
\end{aligned}
$$

As with other positive charge carriers [22], $\mathrm{PF} 2 / 6^{+}$is expected to have another band at low energies. Unfortunately we were not able to see this as our detector cannot measure above $1250 \mathrm{~nm}$, so can only limit this low energy transition to $<1 \mathrm{eV}$.

The value $G=1.6$ (number of species produced per $100 \mathrm{eV}$ of absorbed dose) has been determined for $\mathrm{CHCl}_{3}{ }^{+}$formation on radiolysis of chloroform. Over the range from 2 to 20 Grays (corresponding to solvent radical cation concentrations $4 \times 10^{-7}-4 \times 10^{-6} \mathrm{M}$ ), the absorption at $560 \mathrm{~nm}$ increased linearly with radiation dose.

At the lowest dose used (2 Gray) there appeared to be a very slight grow-in ( $\leqslant 5 \mu \mathrm{s})$ of the $560 \mathrm{~nm}$ absorption. A rate constant $k=1.3 \times 10^{9} \mathrm{M}^{-1} \mathrm{~s}^{-1}$ (in terms of monomer unit concentration) has been reported for the reaction of benzene radical cation with PF2/6 [20]. Assuming that the rate is similar for reaction with chloroform radical cation and using the molecular weight and concentration of the polymer solution, the lifetime for the grow-in at this dose is estimated to be ca. $2-3 \mu \mathrm{s}$, in agreement with this grow-in being due to reaction (2). Some decay of the $560 \mathrm{~nm}$ absorption was observed over a few $100 \mu$ s. However, the spectral shape did not change, and it is likely that this is due to reaction of the positive charge carrier with impurities or species produced in the radiolysis of chloroform.

A band at $2.1 \mathrm{eV}$ has been observed in steady state spectra of PF2/6 films using either photoinduced absorption or chemical oxidation and assigned to the positive charge carrier [29]. Spectral shifts of ca. $100 \mathrm{meV}$ to higher energies are frequently observed with the triplet states of conjugated polymers on going from film to solution [30], and agreement between these and our results is excellent. In photoinduced absorption measurements, the upper polaron band in poly(9,9-dioctylfluorene) films has been reported as a very weak, sharp absorption at $1.95 \mathrm{eV}(635 \mathrm{~nm})$ in spun films containing the so-called $\beta$ phase [31]. The shift of the band to lower energies in this case may well reflect a more ordered structure of the polymer chain.

In our experiments, from the polymer molar concentration and the yield of solvent radical cation, there is always less than one positive charge (hole) per chain (low radiation doses). Using TTA as dosimeter, and taking a molar absorption coefficient for TTA radical cation $\epsilon=21900 \mathrm{M}^{-1} \mathrm{~cm}^{-1}$ from [27], a molar absorption coefficient was determined for the positively 
charged PF2/6 species. The difficulties of defining a molar absorption coefficient for conjugated polymers have been discussed in detail elsewhere [32], and we have chosen to express polymer concentrations in terms of the number of conjugation segments, which are given by the number of positive charges accepted by the polymer. A value at $560 \mathrm{~nm}$ of $2350 \mathrm{dm}^{3}$ (mol conjugation segment $)^{-1} \mathrm{~cm}^{-1}$ was estimated, assuming complete trapping of positive charge from the solvent by the polymer.

The oxidation potential of PF2/6 $\left(E_{\mathrm{ox}}^{\mathrm{o}}=1.08 \mathrm{~V}\right.$ vs. $\mathrm{Ag} / \mathrm{AgCl})$ is higher than that of TTA $\left(E_{\mathrm{ox}}^{\mathrm{o}}=0.67 \mathrm{~V}\right.$ vs. $\mathrm{Ag} / \mathrm{AgCl}$ ) [13]. Following pulse radiolysis of argon saturated chloroform solutions containing various concentrations of PF $2 / 6$ and TTA, the $560 \mathrm{~nm}$ absorption was replaced by an absorption at $670 \mathrm{~nm}$, assigned to the TTA $^{++}$radical cation (Fig. 3) [27]. For clarity, the spectrum is shown at high TTA concentration, where a large percentage of TTA radical cation formation is due to direct capture of positive charge from solvent radical cations by the amine. However, the existence of electron transfer from the amine to PF2/6 positive charge carrier (which is equivalent to hole transfer in the other direction) was confirmed at the highest polymer concentration $\left(200 \mathrm{mg} \mathrm{dm}^{-3}\right)$ and lowest TTA concentration $(0.1 \mathrm{mM})$ by the observation of decay of the PF2/6.+ absorption at $560 \mathrm{~nm}$ matching the grow-in of the TTA $^{+}$absorption at $670 \mathrm{~nm}$ (Fig. 3, inset). From the kinetic curves, a bimolecular rate constant of $5.4 \times 10^{9}$ $\mathrm{M}^{-1} \mathrm{~s}^{-1}$ was estimated for the reaction

$\mathrm{PF} 2 / 6^{+}+\mathrm{TTA} \rightarrow \mathrm{PF} 2 / 6+\mathrm{TTA}^{+}$

This can be compared with the rate constant for a diffusion controlled process in chloroform of $1.2 \times 10^{10}$ $\mathrm{M}^{-1} \mathrm{~s}^{-1}$ [33].

Intramolecular electron (or hole) transfer was studied in the amine end-capped polyfluorene PF2/6am4. The

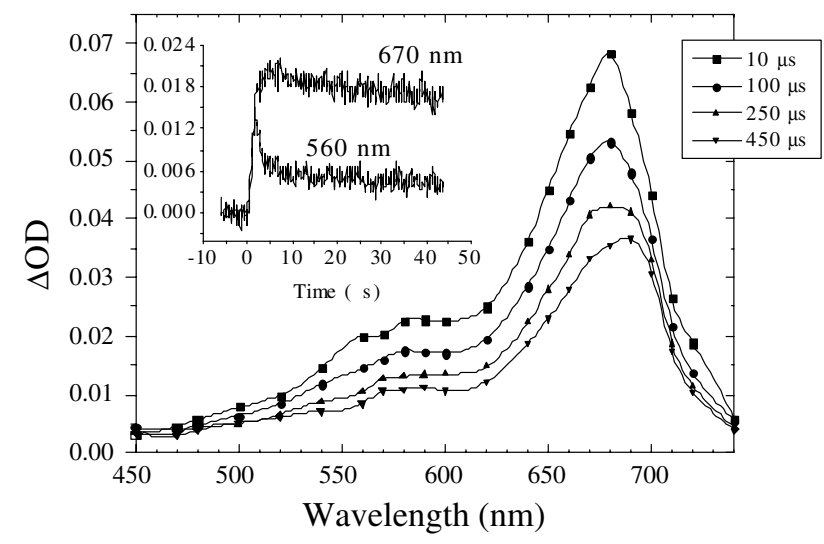

Fig. 3. Spectral data observed following pulse radiolysis of an argon saturated solution of PF2/6 $\left(50 \mathrm{mg} \mathrm{dm}^{-3}\right)$ and TTA $(5 \mathrm{mM})$ in chloroform. Inset: decay of absorptions of PF $2 / 6$ positive charge carrier at $560 \mathrm{~nm}$ and grow in of TTA radical cation at $670 \mathrm{~nm}$ following pulse radiolysis of an argon saturated solution of PF2/6 $\left(200 \mathrm{mg} \mathrm{dm}^{-3}\right)$ and TTA $(0.1 \mathrm{mM})$ in chloroform. end-cap has a very similar structure to TTA, and its oxidation potential $\left(E_{\mathrm{ox}}^{\mathrm{o}}=0.68 \mathrm{~V}\right.$ vs. $\left.\mathrm{Ag} / \mathrm{AgCl}[13]\right)$ is virtually identical. Following pulse radiolysis of an argon saturated solution of PF2/6am4 $\left(200 \mathrm{mg} \mathrm{dm}^{-3}\right)$ in chloroform, a transient absorption was observed with maximum at $680 \mathrm{~nm}$ (Fig. 4). Studies of the absorption at $680 \mathrm{~nm}$ as a function of time show that this species is fully formed within the response time of the experimental system (at the lowest radiation doses used, 2 Gray, this is $\leqslant 500 \mathrm{~ns}$ ), and that it decays by first order kinetics with $k=6.61 \times 10^{3} \mathrm{~s}^{-1}$. Attempts to observe absorption attributable to positive charge on the polyfluorene chain were unsuccessful, since there was no sign of any decay within the system response time at $560 \mathrm{~nm}$, where this species would be expected to absorb. However, because the amine group of PF2/6am4 is chemically very similar to TTA it is possible to estimate how much of the positive charge is produced by direct oxidation of the end-cap by solvent radical cations and how much comes via electron transfer from the poly(fluorene) chain to $\mathrm{CHCl}_{3}{ }^{+}$followed by electron transfer from end-cap to the chain (see Scheme 1). To do this we assume that TTA and end-cap are oxidised at the same rate by the solvent radical cation, and that the molar absorption coefficient of oxidised amine end-cap at $680 \mathrm{~nm}$ is the same as that for the $\mathrm{TTA}^{++}$radical cation. The molar concentration of end-cap in solution was calculated from the polymer concentration $(20 \mathrm{mg} / 100$ $\mathrm{mL}$ ) and the monomer/end-cap feed ratio. An equivalent concentration of TTA $\left(2 \times 10^{-5} \mathrm{M}\right)$ was studied under identical conditions. At the same radiation dose, the absorption observed on pulse radiolysis of the argon saturated solution of PF2/6am4 in chloroform at $680 \mathrm{~nm}$ is at least 2-3 times greater than that of the equivalent concentration of TTA. This must imply some initial trapping of the positive charge by the polymer backbone, followed by rapid ( $\leqslant 500 \mathrm{~ns}$ ) transfer to the end groups.

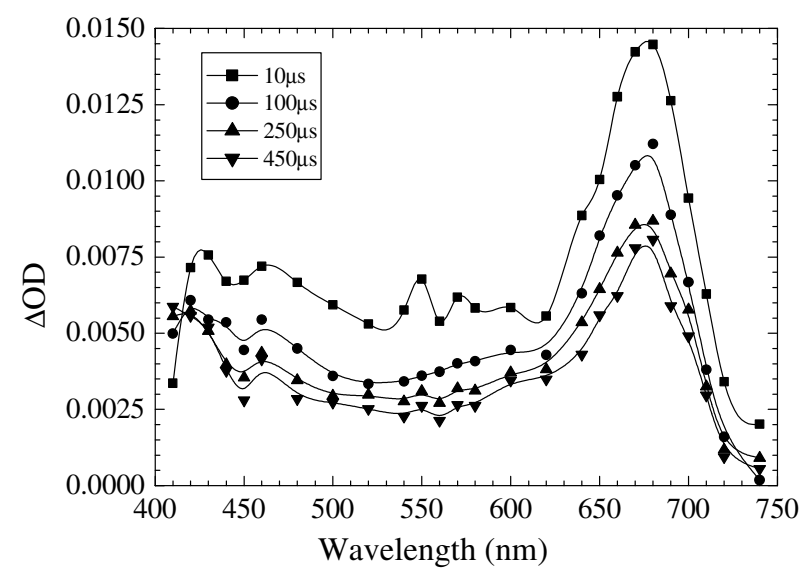

Fig. 4. Spectral data observed following pulse radiolysis of an argon saturated solution of PF2/6am4 (200 $\left.\mathrm{mg} \mathrm{dm}^{-3}\right)$ in chloroform. 


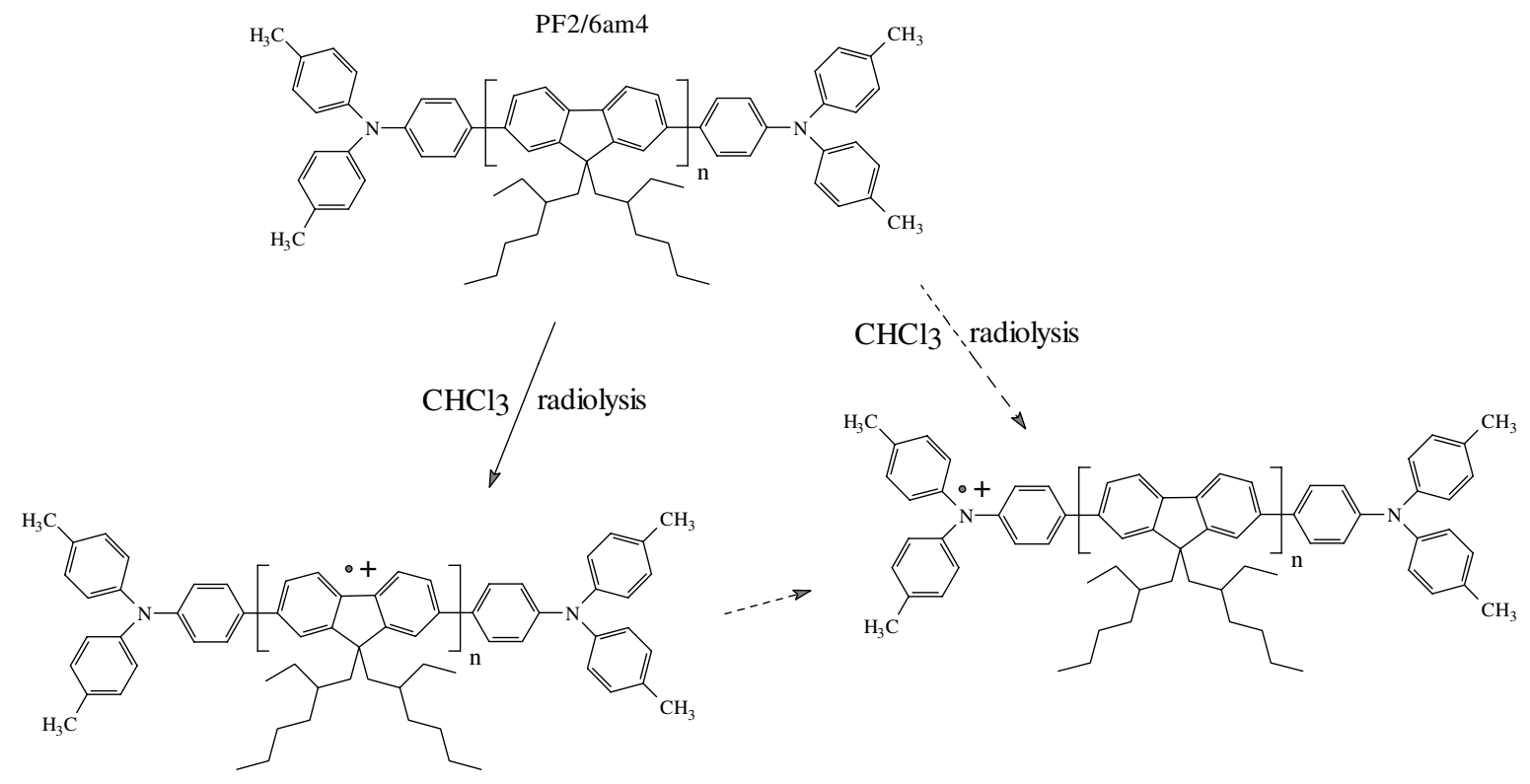

Scheme 1.

This is consistent with the reported mobility $(\mu)$ of positive holes on isolated PF2/6 chain obtained by timeresolved microwave conductivity [20]. Rough calculations were made on the rate of hole transfer in PF2/ 6am 4 calculating the diffusion coefficient, $D$, from the $\mu$ given by Grozema et al. [20] and using the NernstEinstein relationship [34]

$\mu=e_{0} D / k_{\mathrm{B}} T$,

where $e_{0}$ is the elementary charge, $k_{\mathrm{B}}$ the Boltzmann constant, $T$ the absolute temperature, and assuming that this is related to the mean square displacement $\left\langle x^{2}(t)\right\rangle$ by

$D=\left\langle x^{2}(t)\right\rangle / 2 t$.

This displacement is taken as the distance from the centre of the polymer chain to the end-cap estimated to be $320 \AA$ from molecular modelling of related polymers [24], from which it is found that hole transport from the chain to the end-cap in PF2/6am4 is likely to be complete within a few hundred ps, explaining why we were not able to observe this charge transfer directly.

In conclusion, we have characterised the spectral signature of the positive charge carrier in isolated chains of poly[9,9-di(ethylhexyl)fluorene], and have shown that positive charge transfer from the polymer to triarylamine groups occurs either intermolecularly, or, in the case of amine end-capped polymers, intramolecularly. The polaron absorption is far stronger than that found in the solid state [35], with its lifetime also being orders of magnitude longer. Given the potential high polaron diffusivity this would also imply that in the solid, polaron motion is also very rapid, both by intra and inter chain processes, leading to rapid quenching or recombination. Further, in the case of the amine end-capped
PF2/6am4, the polyfluorene chain amplifies the trapped charge population, as a higher absorption is observed from the positively charged triarylamine end-cap than from an equivalent concentration of the model compound TTA in solution. In LEDs using this polymer, holes can become weakly trapped by the amine end-cap, and the increase in efficiency of electroluminescence results from the recombination of these with electrons. However, it is not at present clear whether exciton formation will occur at the end-cap or on the polymer chain.

\section{Acknowledgements}

Pulse radiolysis experiments were carried out at the Free Radical Research Facility in the Synchrotron Radiation Department of the CLRC Daresbury Laboratory, Warrington, UK, with the support of the European Commission through the 'Improving Human Potential' Transnational Access to Major Research Infrastructures Contract HPRI-CT-2002-00183. We to are grateful to POCTI, FCT, FEDER and the Royal Society for further funding. APM acknowledges the Leverhulme Trust for a Fellowship. We also thank Dr. N. Zaidi for purification of solvents.

\section{References}

[1] Chemistry in Britain, June 2002, p. 16.

[2] H. Kobayashi, S. Kanbe, S. Seki, H. Kigchi, M. Kimura, I. Yudasaka, S. Miyashita, T. Shimoda, C.R. Towns, J.H. Burroughes, R.H. Friend, Synth. Met. 111-112 (2000) 125. 
[3] Y. Ohmori, M. Uchida, K. Muro, K. Yoshino, Jpn. J. Appl. Phys. Part 2 - Letters 30 (1991) L1941.

[4] A.W. Grice, D.D.C. Bradley, M.T. Bernius, M. Inbasekaran, W.W. Wu, E.P. Woo, Appl. Phys. Lett. 73 (1998) 629.

[5] U. Lemmer, S. Heun, R.F. Mahrt, U. Scherf, M. Hopmeier, U. Siegner, E.O. Göbel, K. Müllen, H. Bässler, Chem. Phys. Lett. 240 (1995) 373.

[6] M. Leclerc, J. Polym. Sci. Pol. Chem. 39 (2001) 2867.

[7] U. Scherf, E.J.W. List, Adv. Mater. 14 (2002) 477.

[8] S.I. Hintschich, C. Rothe, S. Sinha, A.P. Monkman, P.S. de Freitas, U. Scherf, J. Chem. Phys. 119 (2003) 12017.

[9] D.V. Khramtchenkov, V.I. Arkhipov, H. Bässler, J. Appl. Phys 81 (1997) 6954.

[10] D. Sainova, T. Miteva, H.G. Nothofer, U. Scherf, I. Glowacki, J. Ulanski, H. Fujikawa, D. Neher, Appl. Phys. Lett. 76 (2000) 1810.

[11] L.C. Palilis, D.G. Lidzey, M. Redecker, D.D.C. Bradley, M. Inbasekaran, E.P. Woo, W.W. Wu, Synth. Met. 111-112(2000) 159.

[12] M. Redecker, D.D.C. Bradley, M. Inbasekaran, W.W. Wu, E.P. Woo, Adv. Mater. 11 (1999) 241.

[13] T. Miteva, A.. Meisl, W. Knoll, H.G. Nothofer, U. Scherf, D.C. Müller, K. Meerholz, A. Yasuda, D. Neher, Adv. Mater. 13 (2001) 565.

[14] C. Ego, A.C. Grimsdale, F. Uckert, G. Yu, G. Srdanov, K. Müllen, Adv. Mater. 14 (2002) 809.

[15] S. Janietz, D.D.C. Bradley, M. Grell, C. Giebeler, M. Inbasekaran, E.P. Woo, Appl. Phys. Lett. 73 (1998) 2453.

[16] E.T. Seo, R.F. Nelson, J.M. Fritsch, L.S. Marcoux, D.W. Leedy, R.N. Adams, J. Am. Chem. Soc. 88 (1966) 3498.

[17] M. Grell, D.D.C. Bradley, X. Long, T. Chamberlain, M. Inbasekaran, E.P. Woo, M. Soliman, Acta Polym. 49 (1998) 439.

[18] M. Grell, W. Knoll, D. Lupo, A. Meisel, T. Miteva, D. Nehar, H.G. Nothofer, U. Scherf, H. Yasuda, Adv. Mater. 11 (1999) 671.

[19] M. Redecker, D.D.C. Bradley, M. Inbasekaran, E.P. Woo, Appl. Phys. Lett. 73 (1998) 1565.
[20] F.C. Grozema, L.D.A. Siebeles, J.M. Warman, S. Seki, S. Tagawa, U. Scherf, Adv. Mater. 14 (2002) 228.

[21] R.J.O. Hoofman, M.P. de Haas, L.D.A. Siebbeles, J.M. Warman, Nature 329 (1998) 54.

[22] H.D. Burrows, M. da, G. Miguel, A.P. Monkman, L.E. Horsburgh, I. Hamblett, S. Navaratnam, J. Chem. Phys. 112 (2000) 3082.

[23] T. Yamamoto, Prog. Polym. Sci. 17 (1992) 1153.

[24] G. Lieser, M. Oda, T. Miteva, A. Meisel, H.G. Nothofer, U. Scherf, D. Neher, Macromolecules 33 (2000) 4490.

[25] D.J. Holder, D. Allan, E.J. Land, S. Navaratnam, European Particle Accelerator Conference 2002, Paris. Available from $<$ http://www.frrf.dl.ac.uk/MOPLE116.pdf>.

[26] J. Butler, B.W. Hodgson, B.M. Hoey, E.J. Land, J.S. Lea, E.J. Lindley, F.A.P. Rushton, A.J. Swallow, Radiat. Phys. Chem. 34 (1989) 633.

[27] H.D. Burrows, D. Greatorex, T.J. Kemp, J. Phys. Chem. 76 (1972) 20.

[28] P.W.F. Louwrier, W.H. Hamill, J. Phys. Chem. 73 (1969) 1702.

[29] A. Pogantsch, F.P. Wenzl, U. Scherf, A.C. Grimsdale, K. Müllen, E.J.W. List, J. Chem. Phys. 119 (2003) 6904.

[30] A.P. Monkman, H.D. Burrows, M.G. Miguel, I. Hamblett, S. Navaratnam, Chem. Phys. Lett. 307 (1999) 303.

[31] A.J. Cadby, P.A. Lane, H. Mellor, S.J. Martin, M. Grell, C. Giebeler, D.D.C. Bradley, M. Wohlgenannt, C. An, Z.V. Vardeny, Phys. Rev. B 62 (2000) 15604.

[32] J. Seixas de Melo, H.D. Burrows, M. Svenson, M.R. Anderson, A.P. Monkman, J. Chem. Phys. 118 (2003) 1550.

[33] S.L. Murov, I. Carmichael, G.L. Hug, Handbook of Photochemisry, second edn., Marcel Dekker, New York, 1993, p. 208.

[34] R. Kubo, J. Phys. Soc. Jpn. 12 (1957) 570.

[35] M. Ariu, D.G. Lidzey, M. Sims, A.J. Cadby, P.A. Lane, D.D.C. Bradley, J. Phys. Condens. Matter 14 (2002) 9975. 